\title{
Hare's Error
}

\section{Dawn M. Gale \\ University of Kansas}

A large portion of the work of moral philosopher R. M. Hare presents his attempt to ground normative ethics on metaethicsthe logic of moral reasoning and the meanings of the moral words. According to Hare's metaethical analysis, moral judgments are to be understood in terms of universal prescriptivism, which yields an act utilitarian account of morality at the normative level. While I find many attractive features in Hare's account of normative ethics, I believe Hare fails to demonstrate that the logical analysis of the moral concepts entails the normative theory he defends. The act utilitarian principle of morality is at best merely one possible principle that derives support from or is consistent with a Harean account of metacthics. As it stands, Hare's metaethical analysis is incapable of grounding any specific normative theory on its own.

According to Hare's account of moral philosophy, the first steps in confronting and resolving moral issues call for an understanding of the meanings of the moral words and the logical properties that govern rational thought about moral questions. ${ }^{1}$ Hare emphasizes that "we come into moral philosophy asking certain moral questions, and the questions are posed in terms of certain concepts. If we go on trying to answer those questions, we are stuck with those concepts." 2 Thus Hare focuses on concepts such as ought and wrong, concepts that people actually use in the moral questions they ask. He maintains that understanding the meanings of such terms will yield certain logical properties, which in turn will determine the answers offered to these questions at the normative level. Since my concern focuses on Hare's move from the metaethical to the normative, it is crucial to examine the logical properties that give rise to our normative conclusions on Hare's account.

Hare introduces three logical properties of moral judgments: universalizability, prescriptivity, and overridingness. According to 
Hare, these three features of moral judgments restrict the manner in which we can think rationally about issues of morality. Furthermore, the properties of universalizability and prescriptivity taken together will ultimately determine the normative principles we use to guide our actions, specifically, act utilitarianism on Hare's account. I currently remain neutral on the merits of Hare's analysis of the moral words to yield these three properties. For purposes of argument in this paper, I am willing to accept his use of these properties. However, I will argue that even if Hare's tripartite analysis of moral language is correct, Hare is mistaken in his conclusion that the properties of universalizability and prescriptivity taken together yield the equivalent of act utilitarianism at the level of normative ethics. In order for my argument to proceed, it is necessary to consider each of the logical properties of moral judgments that Hare sets forth along with the practical implications that follow from them. I will first turn to universalizability.

In Moral Thinking, Hare describes the universalizability of moral judgments in the following manner.

Universalizability can be explained in various equivalent ways; it comes to this, that if we make different moral judgements about situations which we admit to be identical in their universal descriptive properties, we contradict ourselves. By 'different', I mean 'such that, if they were made about the same situation, they would be inconsistent with one another'. ${ }^{3}$

He spells out this condition in his earlier book Freedom and Reason. Hare claims, "If a person says 'I ought to act in a certain way, but nobody else ought to act in that way in relevantly similar circumstances', then on my thesis he is abusing the word 'ought'; he is implicitly contradicting himself." "Thus, the universalizability property of moral judgments places certain restrictions on our use of moral language and the types of judgments we can make about like cases. Essentially, the universalizability requirement calls for us to treat like cases alike, upon pain of contradiction.

Hare is careful to emphasize that universalizability is not the same as generality. ${ }^{5} \mathrm{He}$ claims, "Briefly, generality is the opposite 
of specificity, whereas universalizability is compatible with specificity, and means merely the logical property of being governed by a universal quantifier and not containing individual constants."' Hare offers an example to illustrate his point. He says, "The two principles 'Never kill people' and 'Never kill people except in self-defense or in cases of adultery or judicial execution' are both equally universal, but the first is more general (less specific) than the second." This reiterates Hare's earlier point that the notion of universalizability involves treating all relevantly similar cases the same regardless of how general or specific our moral judgments may be. This point is drilled home once again when Hare writes, "Moral judgements are, I claim, universalizable in only one sense, namely that they entail identical judgements about all cases identical in their universal properties." ${ }^{8}$ We shall soon see that this, according to Hare, will have certain implications for the moral judgments we can rationally make, when combined with the prescriptive element of moral judgments. First, it is necessary to consider what the property of prescriptivity itself entails.

According to Hare, "The prescriptivity of moral judgements can be explained formally as the property of entailing at least one imperative." However, Hare believes that offering an account of prescriptivity in terms of imperatives will be too difficult. Thus, he explains prescriptivity in the following manner. "We say something is prescriptive if and only if, for some act A, some situation $\mathrm{S}$, and some person $\mathrm{P}$, if $\mathrm{P}$ were to assent (orally) to what we say, and not, in $\mathrm{S}$, do $\mathrm{A}$, he logically must be assenting insincerely." ${ }^{10}$ Hare offers the following example for clarification:

The mere fact that what we say could be given as a reason for acting in some way does not make it prescriptive. That the hotel faces the sea could be given as a reason for taking a room there, but to say that it does is not to say something prescriptive; for somebody who did not like looking at the sea could sincerely assent, and yet not take a room there. On the other hand if we say that it is a better hotel than the one on the other side of the road, there is a sense of 'better than' (the prescriptive sense) in which a person who assented orally to our judgement, yet when 
faced with a choice between the two hotels (other things such as price being equal), chose the other hotel, must have been saying something he did not really think. For if, in assenting, he assented sincerely to something prescriptive, he must think it better, and thus prefer it, and thus in the appropriate and other things being equal, choose it. The example could easily be adapted to make a similar point about the prescriptivity, in certain uses of 'right', 'ought', and (a fortiori) 'must'."

The significant element of Hare's example shows that when one offers a prescription, he or she is making some kind of evaluation or stating a preference from something. The significance of this point becomes apparent when we examine the logical properties of universalizability and prescriptivity taken together.

Thus far we have examined two logical properties of moral judgments, universalizability and prescriptivity. The universalizability requirement calls for those of us making moral judgments to treat relevantly similar cases in the same ways. The prescriptivity requirement calls for us to recognize that moral judgments state preferences of those making the moral judgments. When we bring these two components together, we will find that in making moral judgments there is a requirement to universalize our prescriptions. According to Hare we will find "that the requirement to universalize or prescriptions, which is itself is a logical requirement if we are reasoning morally, demands that we treat other people's prescriptions (i. c. their desires, likings, and, in general preferences) as if they were our own."12 This feature of moral judgments derived from the logical properties will serve as the basis of Hare's account of normative ethics. Prior to examining Hare's move from metaethics to normative ethics, we should briefly mention the final logical property of moral words according to Hare's metaethical analysis, overridingness.

For our purposes, it is significant to have some notion of what Hare means by overridingness merely to clarify that overridingness plays no role in his attempt to establish act utilitarianism from metaethical analysis. On Hare's account, overridingness serves to distinguish moral judgments from other evaluative judgments. He writes, "To treat a principle as overriding, then, is to let it always 
override other principles when the conflict with it, and in the same way, let it override all other prescriptions, including nonuniversalizable ones (e.g. plain desires). ${ }^{.13}$ During this discussion, Hare notes that while overridingness is an important property of a moral judgment for purposes of distinction, it does not play a role in his argument that the logical properties of the moral words yield an act utilitarian account of normative ethics. This argument is left to the other properties of the moral words, universalizability and prescriptivity. ${ }^{14}$

It is Hare's contention that the formal logical properties of the moral words, universalizability and prescriptivity, yield a system of moral reasoning identical with act utilitarianism..$^{15}$ It is important to note that on Hare's account utilitarianism is composed of two elements, a formal element, which Hare describes as "a reformulation of the requirement that moral principles be properly universal" and a substantial element that the determination of what we ought to do requires the consideration of the preferences of all those who will be affected by our actions, a factor that corresponds to Hare's account of prescriptivity. ${ }^{16}$ Given these two elements, it is not surprising that Hare argues that utilitarianism follows from the logical properties of the moral words that he has introduced in his metaethical analysis. Thus, let us consider his argument.

Hare maintains that:

We shall see that the method of critical thinking which is imposed on us by the logical properties of the moral concepts requires us to pay attention to the satisfaction of the preferences of people (because moral judgements are prescriptive, and to have a preference is to accept a prescription); and to pay attention equally to the equal preferences of all those affected (because moral judgments have to be universal and therefore cannot pick out individuals). ${ }^{17}$

It is when we apply this model of moral thinking to actual cases to determine what ought to be done in given circumstances that we see how the requirement to universalize our prescriptions generates utilitarianism on Hare's account. Before turning to one of Hare's practical examples to see how universal prescriptivism leads to 
act utilitarianism, let us consider the requirements that the logical properties set forth in connection with act utilitarianism.

First, Hare maintains that the prescriptivity element of moral judgments requires us to consider the preferences of those who might be affected by our actions. Second, as Hare states, "It follows from universalizability that if I now say that I ought to do a certain thing to a certain person, I am committed to the view that the very same thing ought to be done to me, were I in exactly his situation, including having the same personal characteristics and in particular the same motivational states." ${ }^{\prime 8}$ But, as Hare points out, if I were in his shoes, it is likely that my motivational state would be different than the motivational state I have in my own position. Thus, if I am to consider his preferences as well as my own, as universal prescriptivism requires, conflict between the two sets of preferences will follow." Thus, we must determine how to resolve the conflict between the two sets of preferences while at the same time preserving the logical character of the moral concepts as universal and prescriptive.

At this point, if we turn to Hare's example, we shall see not only the conflict resolution, but also Hare's account of how universal prescriptivism generates act utilitarianism. Consider the following scenario. Hare is in a situation where in order to park his car; he must move someone else's bicycle. Yet, the other person has some aversion to his bicycle being moved. ${ }^{20}$ Hare claims that we can resolve this case in the same manner that we resolve conflicts between our own preferences. In such cases, we consider all of the preferences equally and the strongest overall preference wins out. When applied to the car versus bicycle case, Hare offers the following account:

The other party wants me not to move his bicycle, but I want more to move it in order to park my car. I am fully aware of the strength of his desire, and therefore have a desire of equal strength that were I in his situation, the bicycle should stay where it is. But I also have my original desire to move it in order to park my car. This latter desire wins by superior strength. On the other hand, if the positions were reversed (the bicycle mine, the car his), and I could somehow prevent the bicycle being moved, 
the case would be from my individual point of view different (though it is not different in its universal properties). Suppose that, in this different case, my desire not to have the bicycle moved is far weaker than the other party's desire to park his car; and suppose I am fully aware of the strength of his desire and therefore have an equal desire that, were $I$ in his position I should be able to park my car. I shall then, in this different situation have again two desires: the original desire to leave my bicycle where it is, and my acquired desire that were I the other party I should be able to park my car; and the latter will be the stronger. So in this different situation I shall think that the bicycle ought to be moved. ${ }^{21}$

What is seen in Hare's example is the role of both the prescriptivity and universalizability of the judgment (both Hare's preferences and the other's preferences are considered with the strongest preference determining the action that ought to be done). On Hare's account, "We see here in miniature how the requirement to universalize our prescriptions generates utilitarianism."22 If we impartially compare the strengths of preferences between Hare and the owner of the bicycle with the strongest preferences winning out our conclusion is the same as that of act utilitarianism. Each system weighs the different sets of preferences against one another and the strongest overall preferences determine the right action in a given situation. Thus, when we combine the requirements of the two logical properties of moral judgments, universalizability and prescriptivity, we are committed to an act utilitarian account of normative ethics.

Now that we have examined the logical properties of the moral words and Hare's move from these propertics to the principle of act utilitarianism at the normative level, we can examine the success of Hare's argument and his use of metaethics as the foundation of his normative theory. It is my contention that Hare's metaethical analysis as it stands fails to ground act utilitarianism or any other single normative theory. ${ }^{23}$ Rather it opens the door to a number of competing theories that may be established by adding additional premises to the metaethical analysis offered by Hare. In fact, by examining Hare's own account of the logic of the moral words 
and the examples he considers, it is clear that his metaethics fails to ground the act utilitarian conclusions he advocates.

As we have seen so far, Hare maintains that the meanings of the moral words give rise to the logical properties of universalizability and prescriptivity, which in turn govern the kind of moral judgments we may rationally make. Universalizability requires that we assess cases that are alike in their universal properties in the same way. Prescriptivity brings the expression of preferences into moral judgments. When we combine these two features on Hare's account, there is a logical requirement to consider everyone's preferences. For purposes of argument, I am perfectly willing to grant Hare's premises as they are presented above. However, Hare goes on to argue that these assumptions are sufficient to establish an act utilitarian account of normative ethics; it is this conclusion that I wish to reject.

In order for us to derive act utilitarianism out of Hare's account, it must be the case that we consider everyone's preferences equally and impartially with no one's preferences counting for any more than anyone else's preferences. It is clear that Hare believes this consideration to be captured by his account of metaethics. Recall a passage from Hare that I cited earlier that claims:

...the method of critical thinking which is imposed on us by the logical properties of the moral concepts requires us to pay attention to the satisfaction of the preferences of people (because moral judgements are prescriptive, and to have a preference is to accept a prescription); and to pay attention equally to the equal preferences of all of those affected (because moral principles have to be universal and therefore cannot pick out individuals)..$^{24}$

In this passage, we see clearly Hare's belief that the equal consideration of everyone's preferences follows from the universalizability of the prescription. This is also evident in Hare's example comparing his own preferences with those of the bicycle owner. In that case, neither the interests of Hare, nor those of the bicycle owner were given any special weight or priority; both parties' interests were considered equally and impartially. Hare 
becomes more explicit about the equal consideration of everyone's preferences in Moral Thinking when he claims:

In estimating the preferences of others, and my future preferences, I have, then, to keep my own antecedent present preferences out of the reckoning. This does not mean that my own preferences play no part in moral thinking. The argument of ch. 6 required us to be impartial between our own and other people's preferences, not altruistic in its correct sense of giving more weight to the preferences of others. We have to treat everybody as one, including ourselves: to do so unto others as we wish they should do unto us (sc. in their situations with their preferences), and love our neighbors as (not more than) ourselves. We get no extra weight for our own preferences because we are doing the moral thinking, but they get equal weight with those of others in so far as we are affected parties. ${ }^{25}$

It once again becomes obvious that in Hare's estimation, universal prescriptivism requires the equal consideration of everyone's preferences and thus yields a utilitarian account of normative ethics, for utilitarianism assesses morality in terms of the equal consideration of everyone's preferences.

The difficulty arises when we raise the issue of where the notion of equal consideration comes into Hare's theory. As the element of prescriptivity merely brings in the notion that the expression of preferences is an element of moral judgment, it is up to the notion of universalizability to bring in the idea of equal consideration. From the passages just mentioned, it seems clear that Hare sees the notion of equal consideration as originating from the universalizability requirement. This is explicit when we consider a passage from Freedom and Reason where Hare maintains that the utilitarian principle, 'Everybody to count for one, nobody for more than one' can be justified by the demand for universalizability. ${ }^{26} \mathrm{He}$ argues:

For what this principle means is that everyone is entitled to equal consideration, and that if it is said that two people ought to be treated differently, some difference must be cited as the grounds for these different moral judgements. And this is a 
corollary of the requirement of universalizability. It must be emphasized that it, like the principle of universalizability itself, is a purely formal principle, following from the logical character of the moral words; no substantial moral judgements follow from it unless the substance is put in by arguments such as we have suggested\%and these require other ingredients besides logic, as we have seen $(6.3,4)$. The substance of moral judgements of a utilitarian comes from a consideration of the substantial inclinations and interests that people actually have, together with the formal requirement that the prescriptions which they prompt have to be universalizable before moral judgements can be made out of them. ${ }^{27}$

This passage emphasizes Hare's belief that the element of equal consideration is entailed by the property of universalizability. Thus when we combine this with prescriptivity on his account it may be seen that the logic of the moral words calls for us to consider everyone's preferences equally\%an ingredient I earlier claimed was essential in Hare's attempt to ground utilitarianism on his system of metaethics. If Hare were correct in his claim that universalizability entails equal consideration then the difficulty would be avoided. However, this understanding of universalizability offers a much richer account than Hare has set forth or seems to commit to.

At this point, it is important to note that Hare himself argues, "Moral judgements are, I claim, universalizable in only one sense, namely that they entail identical judgements about all cases identical in their universal properties." 28 This characterization of the universalizability requirement makes no mention of the element of equal consideration nor does such an element seem to be entailed by this account. All this characterization of universalizability implies is that if we consider people's interests equally in one case to determine the morally appropriate action then we must consider people's interests equally in all relevantly similar cases. If a case is such that there is a relevant difference from the first, it may well be that we are not required to consider everyone's preferences equally. If there are grounds for giving more weight to one person's preferences than another's such consideration is permitted by the universalizability requirement as long as this case is different in 
its universal properties from the first case. All universalizability requires is that like cases are treated alike; if there are relevant differences between the cases there may well be differences in the way they are treated. Furthermore, universalizability makes no claims about treating everyone's preferences equally to begin with. We can offer moral judgments that weigh one party's interests more than another's interests as long as we do the same in all relevantly similar cases as all universalizability requires is that we treat like cases alike.

That Hare is committed to this weaker notion of universalizability is evident in his discussion of the fanatic Nazi who offers prescriptions that Hare characterizes as universal but clearly fail to employ the element of equal consideration Hare wants to believe follows from universalizability. The fanatic Nazi desires that Jews be exterminated despite the obvious and perhaps even stronger desire of the Jew not to be exterminated. Furthermore, the extreme fanatic Nazi, however rare they may be in actuality, is in theory unwilling to let go of his convictions and thus perfectly willing to grant that even if he were to occupy the reversed role, that of the Jew, that he too ought to be exterminated even though as a Jew he would surely have a very strong competing desire. According to Hare, the fanatic Nazi offers a universal prescription. He writes:

The important thing for our present argument is that, in this wider sense, the Nazi is desiring that the Jews should be exterminated; and, because the desire is a universal one corresponding to an ideal, he desires that anyone having the characteristics which make him want to exterminate Jews should likewise be exterminated. And from this it follows that, if he is sincere and clear-headed, he desires that he himself should be exterminated if he were to come to have the characteristics of Jews. ${ }^{29}$

While Hare holds that the fanatic Nazi does make a universal prescription, he argues that a truly intractable Nazi, one who will admit that he too should be exterminated if it turns out he is a Jew, is extremely rare.$^{30}$ However, for our purposes the rarity of such people is irrelevant. All that matters to our point of concern is Hare's admission that the fanatic Nazi offers a universal prescription that Jews be exterminated regardless of the preferences 
of the Jew. It is clear from this claim, that the Nazi does not afford the preferences of the Jew as much weight as his own preferences. It is clear that the prescription of the fanatic Nazi while universal on Hare's own admission fails to include the element of equal consideration that Hare claims follows from the property of universalizability. Thus, Hare's discussion of the fanatic Nazi lends further support to the notion that universalizability does not entail equal consideration on Hare's own account of universalizability. Without the claim that everyone's preferences must be considered equally and impartially, Hare's metaethics is unable to generate an act utilitarian account of normative ethics.

There is however, one other move we might consider before rejecting Hare's conclusion completely. If we recall Hare's account of the logical properties of moral judgments as set out at the beginning of this paper, we should remember that universalizability and prescriptivity did not exhaust Hare's list. There was an additional property, overridingness, that Hare introduced. Thus, we must consider the possibility that the overridingness of moral judgments can account for the element of equal consideration, allowing Hare to derive act utilitarianism from his metaethical analysis after all. Nonetheless, if we turn back to our earlier discussion of overridingness (p. 6), we will find that Hare himself admits that this property does not play a role in providing a foundation for his normative theory. ${ }^{31}$ Furthermore, if reflect back on Hare's account of overridingness we will find that, "To treat a principle as overriding, then, is to let it always override other principles when they conflict with it, and in the same way, let it override all other prescriptions, including non-universalizable ones (e.g. plain desires)." ${ }^{32}$ Given this, we will find that it is unlikely that the logical property of overridingness is able to account for the impartiality and equal consideration of preferences that are necessary for Harean metaethics to generate utilitarianism.

Without the element of equal consideration, all that is required by the logic of the moral words as seen in Hare's account of metaethics is that in making moral judgments we consult the preferences of those affected by an action and treat like cases alike. These restrictions do not yield act utilitarianism on their own. Other normative views meet these requirements as well. Hare himself 
admits that the fanatic Nazi is able to meet these conditions. Another possibility is the Rawlsian principle of maximin, which also requires the consideration of everyone's preferences. On this account, however, contrary to that of utilitarianism, not everyone's preferences are to count equally; rather, we are required to give priority to the preferences of the worst off. If all that is required by the logical properties of the moral words is that the preferences of all are considered and like cases are treated alike, the principle of maximin is not excluded by Harean metaethics. Furthermore, any other normative theory that meets the conditions of universalizability, prescriptivity, and overridingness also finds as much support in Hare's account of metaethics as act utilitarianism does.

R. M. Hare devotes a significant portion of his work to his attempt to demonstrate the existence of a metaethical foundation for an act utilitarian account of normative ethics. Specifically, Hare points to the logical properties of universalizability and prescriptivity as entailing the consideration of everyonc's preferences in an equal and impartial manner and thus giving rise to an act utilitarian account of normative ethics. Despite all of his efforts, all Hare actually shows is that the universalizability and prescriptivity of moral judgments require that we consider the interests of everyone. Hare's account of these two features leaves out the further notion of equality and impartiality that he reads into them. Consequently, Hare fails to establish a foundation for the principle of utility in his account of metaethics. At best, Hare offers an account of metaethics that could with additional premises ground any of a variety of moral principles. A reevaluation of Harean metaethics and the search for such additional premises in the logic of the moral words along with an exploration of the normative implications that might result from a revised version of Harean metaethics opens the door to new lines of inquiry for the moral philosopher.

\section{Notes}

' R. M. Hare. 1981. Moral Thinking: Its Levels, Method, and Point (hereafter MT). Oxford University Press, New York, New York, p. 2.

${ }^{2}$ Ibid., 18. 
${ }^{3}$ Ibid., 21.

${ }^{4}$ R. M. Hare. 1963. Freedom and Reason (hereafter FR), Oxford University Press, New York, New York, p. 32.

${ }^{5}$ Hare, $M T, 41$. See also Hare's 1972 article on principles.

${ }^{6}$ Ibid.

${ }^{7}$ Ibid.

${ }^{8}$ Ibid., 108.

${ }^{9}$ Ibid., 21.

${ }^{10} \mathrm{Ibid}$.

"Ibid., 21-22.

12 Ibid., 16-17.

${ }^{13} \mathrm{Ibid}$., 56.

${ }^{14}$ Ibid., 53-54.

${ }^{15}$ Ibid., 4.

${ }^{16}$ Ibid., 4-5.

${ }^{17} \mathrm{Ibid}, 91$.

${ }^{18}$ Ibid., 108.

${ }^{19} \mathrm{Ibid}, \mathrm{,} 108-109$.

${ }^{20}$ Ibid., 109.

${ }^{21}$ Ibid., 110-111.

22 Ibid., 111.

${ }^{23}$ Hare has been criticized on this point previously on at least a couple of occasions. In "The Structure of Hare's Theory" in Douglas Seanor \& N. Fotion (eds.), 1988, Hare and Critics: Essays on Moral Thinking, Oxford University Press, NY, NY, pp. 185-196, Bernard Williams maintains that the logical properties of the moral words are incapable of grounding any single account of normative ethics with the addition of normative premises. In "Justice, Social Contract, and Universal Prescriptivism" in Philosophical Quarterly 28(110):65-73, 1978. M. H. Lessnoff argues that Hare is able to derive normative principles from the logical properties of the moral words; however, Lessnoff holds that Hare is unable to derive the principle of utility but is able to derive something like the Rawlsian principle of maximin. I agree with both Williams and Lessnoff in their claim that Hare is unable to ground act utilitarianism on the logical properties of universalizability and prescriptivity taken together from his metaethical analysis. At this point, however, I remain open to the possibility of grounding the principle of utility or other normative principles of morality on a revised account of Harean metaethics. This separates my view from Williams' perspective that any account of metaethics is incapable of providing a foundation for normative theory without the addition of normative premises. My view is also distinguished 
form Lessnoff's, which holds that the status quo in Hare's metaethics provides enough of a basis to establish a particular normative theory on its own.

${ }^{24}$ Hare, $M T, 91$. My italics.

${ }^{25} \mathrm{Jbid} ., 129$.

${ }^{26}$ Hare, FR, 118.

${ }^{27} \mathrm{Ibid}$.

${ }^{28}$ Hare, $M T, 108$.

${ }^{29}$ Hare, FR, 170.

${ }^{30} \mathrm{Ibid}$., 171.

"Hare, MT, 53-54.

${ }^{32}$ Ibid., 56. 